\title{
Radix Puerariae lobatae (Gegen) suppresses the anticoagulation effect of warfarin: a pharmacokinetic and pharmacodynamics study
}

\author{
Beikang $\mathrm{Ge}^{\dagger}$, Zhen Zhang ${ }^{\dagger}$ and Zhong Zuo*
}

\begin{abstract}
Background: Radix Salvia miltiorrhiza (Danshen) and Radix Puerariae lobatae (Gegen) are used in Traditional Chinese Medicine to treat cardiovascular diseases. However, adverse herb-drug interactions were observed between warfarin and herbal remedies containing Danshen and Gegen. This study aims to investigate the pharmacokinetic and pharmacodynamic interactions between warfarin and the different components found in Danshen and Gegen.

Methods: Sixty Sprague-Dawley rats were used to investigate the effects of warfarin $(0.2 \mathrm{mg} / \mathrm{kg}$ ), Danshen (240 or $480 \mathrm{mg} / \mathrm{kg}$ ) and Gegen (240 or $480 \mathrm{mg} / \mathrm{kg}$ ) both in isolation and combination. The rats in the warfarin and Danshen/ Gegen combination groups were given an oral dose of Danshen or Gegen $2 \mathrm{~h}$ after being given an oral dose of warfarin. After five consecutive days of treatment, the pharmacokinetic interactions between Danshen/Gegen and warfarin were investigated by simultaneously monitoring and comparing the cytochrome P450 (CYP) activities, mRNA and protein expression levels in the livers of the rats from the different treatment groups. The pharmacodynamic interactions were evaluated by monitoring and comparing the vitamin K epoxide reductase (VKOR) activities, mRNA and protein expression levels in the livers of rats from the different groups, as well as the thrombomodulin (TM) activities, mRNA and protein in the lungs of these animals. The rat plasma soluble thrombomodulin concentrations of the different treatment groups were also evaluated. Microsomes incubation, Real Time-Polymerase Chain Reaction and Western blot was applied respectively to study the activity, mRNA expression and protein expression of CYP, VKOR and TM.

Results: The activities and expression levels of the CYP and VKOR enzymes in the warfarin-Gegen combination groups increased by nearly $30 \%(P=0.02)$ compared with the warfarin-alone group, whereas those of TM decreased by almost $25 \%(P=0.02)$. The administration of Danshen did not lead to any changes in the activities or the expression levels of the CYP, VKOR or TM enzymes compared with those of the control group. Gegen induced several warfarin-metabolizing CYP enzymes and neutralized the effects of warfarin towards VKOR and TM.

Conclusion: Gegen, rather than Danshen at the same tested dosage, offsets the anticoagulant effects of warfarin by accelerating the phase I liver metabolism of warfarin, as well as increasing the activity, mRNA and protein expression of VKOR while decreasing those of TM.
\end{abstract}

\section{Background}

The use of the anticoagulant warfarin in combination with herbal remedies has caused several safety concerns

\footnotetext{
*Correspondence: joanzuo@cuhk.edu.hk

${ }^{\dagger}$ Beikang Ge and Zhen Zhang contributed equally to this work

School of Pharmacy, Faculty of Medicine, The Chinese University of Hong

Kong, Shatin, New Territories, Hong Kong, China
}

because of the narrow therapeutic window of warfarin [1]. According to reports from pharmacists in the United Kingdom, about $58 \%$ of patients prescribed warfarin also regularly consumed herbal medicines to manage their conditions [2,3]. A racemic mixture of warfarin consists of a 1:1 mixture of its $R$ - and $S$-enantiomers, which differ considerably in terms of their potency and the rate at 
which they are metabolized [4]. Both of the enantiomers of warfarin are metabolized by cytochrome P450 (CYP) enzymes in a region- and stereo-selective manner, to afford the corresponding 6-, 7-, 8-, 10- and 4'-hydroxywarfarin compounds as the major metabolites [5]. The ingestion of certain plant materials such as grapefruit [6] and garlic $[7,8]$ can have a pronounced effect on the activity and/or expression of the CYP enzymes, which could have serious consequences for the metabolism of warfarin. The co-administration of herbs and drugs can also affect the activity and expression of vitamin $\mathrm{K}$ epoxide reductase (VKOR), which is the target protein of warfarin in terms of its anticoagulant effects. Although there were two separate studies pertaining to the inhibitory activities of the drug-warfarin interactions of paracetamol and sodium dehydroacetate (DHA-S) towards VKOR $[9,10]$, there were studies concerning the impact of herbs on the activity or expression of VKOR. In addition to VKOR, plasmasoluble thrombomodulin TM (sTM), which is the cleavage product of cellular TM [11], could be used as a potential biomarker for identifying patients at high risk of bleeding during warfarin treatment [12-14]. Notably, Salvianolic acid $\mathrm{B}$ led to an increase in the activity and expression of TM in vitro [15]. Danshen-Gegen formula (DGF), which is a herbal medicine containing Radix Salvia miltiorrhiza (Danshen) and Radix Puerariae lobatae (Gegen), led to a 5.36-fold increase in the mRNA expression of TM [16].

DGF, which is the aqueous extract derived of a $7: 3$ (w/w) mixture of Danshen and Gegen, was recently developed in Hong Kong [17]. DGF contains a variety of active components, including danshensu, salvianolic acid B (SAB), protocatechuic aldehyde (PCA), puerarin, daidzin and daidzein [18], and was reported to be an effective agent for the treatment of cardiovascular diseases [19-21]. The results of our previous in vivo study in rats demonstrated that the co-administration of DGF with warfarin led to pronounced herb-drug interactions [22], including a significant decrease in the $\mathrm{C}_{\max }$, area under curve (AUC) and the prothrombin (PT) time of warfarin. Although these changes in the pharmacokinetic properties of warfarin were attributed to the DFG-mediated induction of the CYP enzymes, the precise nature of the herbal components responsible for these induction effects were identified.

Danshen was reported to improve microcirculation, cause coronary vasodilation, suppress the formation of the thromboxane and inhibit the adhesion and aggregation of platelets. Based on its many interesting biological properties, Danshen has been widely used to treat coronary artery disease and numerous other cardiovascular diseases in China, Korea and Japan, as well as several other Asian countries [23-25]. Although the results of several previous studies suggested that Danshen interacts with warfarin by changing its pharmacokinetic and pharmacodynamic parameters [26-29], these studies generally fail to provide dosage information for Danshen. Furthermore, there are several inconsistencies in the findings of these studies. Preclinical studies in this area not reached an agreement on the effects of Danshen on the PT time of warfarin after the co-administration of these agents [30,31]. The discrepancies observed in these pre-clinical and clinical research data could be explained in terms of the differences in the administration routes, dosages and Danshen preparations used in the different studies. In this study, we used an ex vivo approach to mimic the clinical behaviors of warfarin and Danshen and investigate the underlying mechanism of interaction between these two agents. Compared with Danshen, there were very few reports pertaining to the herb-drug interactions of Gegen, which is another major component of DGF. In a similar manner to Danshen, Gegen was reported to improve micro-circulation, increasing blood flow and preventing coronary artery disease [32]. Puerarin and Gegen extract were reported to regulate the activity of certain CYP enzymes in rats [33]. Furthermore, the results of a recent clinical study showed that puerarin induced the activity of CYP1A2 and inhibited the activity of CYP2D6 [34], which indicated that there could be potential interactions between warfarin and Gegen.

Existing mechanistic studies mainly focused on the impact of changes in the pharmacokinetics of warfarin rather than its pharmacodynamics, despite the fact that changes in the latter account for $79.9 \%$ of all the identifiable herb-drug interaction mechanisms [35]. This study aims to investigate the pharmacokinetic and pharmacodynamic interactions between warfarin and Danshen/Gegen. To achieve these goals, we applied an ex vivo approach to investigate the effects of Danshen/ Gegen on the different CYP enzymes involved in the metabolism of warfarin (for pharmacokinetic analysis). We also monitored the effects of Danshen/Gegen on the activities and mRNA and protein expression levels of VKOR and TM (for pharmacodynamic analysis).

\section{Methods}

\section{Herbs}

The concentrated Chinese medicine granules of Danshen (Batch No. 1007) and Gegen (Batch No. 1027) with the extraction ratio of 1:5 were purchased from Nong's Company Limited (Hong Kong). The raw herbs were morphologically authenticated by an in-house herbalist and chemically by the thin layer chromatography in accordance with the Chinese Pharmacopoeia 2005 [36]. The plant names in current study were used according to the latest revision in "The Plant List" (http://www.theplantlist.org). 


\section{Reagents}

Racemic warfarin, diclofenac sodium and naringin (internal standards) were purchased from Sigma-Aldrich (St. Louis, MO, USA). The standards of sodium danshensu, protocatechuic aldehyde, SAB, puerarin, daidzin and daidzein were purchased from Zhongxin Innova Laboratories (Tianjin, China). Phenobarbital (PB), betanaphthoflavone (BNF), cyclophosphamide monohydrate (CPA), bovine serum albumin, S-2238 and human thrombin were purchased from Sigma-Aldrich (St. Louis, MO, USA). Vitamin $K_{1}$ purchased from Sigma was used to prepare vitamin $\mathrm{K}_{1} 2$, 3-epoxide (VKO) by the method of Tishler [37]. Hirudin was purchased from Calbiochem (La Jolla, California, USA). Acetic acid and ethyl acetate were obtained from BDH Laboratory (Poole, England). Acetonitrile and methanol (HPLC grade) were obtained from Tedia Company Inc. (Fairfield, USA) and Fisher Scientific UK Limited (Leicestershire, UK), respectively. All other reagents were analytical or HPLC grade. Distilled and deionized water was used for the preparation of all solutions. $S$-warfarin, $R$-warfarin, and racemic standards of $4^{\prime}-$, 6-, 7-, 8- and 10-OH-warfarin were purchased from Ultrafine Chemicals (Manchester, UK). Both the primary and secondary antibodies of CYP1A1, CYP2B1/2B2, CYP2C6, CYP2C11, VKOR, TM and GAPDH were purchased from Abcam (Abcam Inc., Cambridge, MA). ELISA kits for detecting sTM plasma concentration were purchased from Life Science Inc.

\section{Animals}

Healthy male SD rats (220-250 g) were supplied by the Animal Service Center at the Chinese University of Hong Kong and fasted overnight before use. The experiments were carried out under the approval by the Animal Ethics Committee of the Chinese University of Hong Kong with an approval number of (12-538) in DH/HA\&P/8/2/1 Pt.26 (Additional file 1).

\section{Instruments for sample analyses}

The LC/MS/MS system, used for sample analyses of warfarin and its monohydroxylated metabolites, were performed with an ABI 2000 tandem triple quadruple LC/MS spectrometer equipped with an electrospray ionization source (ESI), two Perkin-Elmer PE-200 series micro-pumps and auto-sampler (Perkin-Elmer, Norwalk, CT, USA). The liquid chromatographic sample analyses instrument for detecting VK and VKO was a Waters HPLC system (Waters, Milford, MA,USA) equipped with 996 photodiode-array detector and 2695 separation module (pump and auto sampler). The chromatographic separation was performed at ambient temperature by X-Bridge ${ }^{\mathrm{TM}} \mathrm{C}_{18}$ column $(150 \times 4.6 \mathrm{~mm}$ i.d., $3.5 \mu \mathrm{m}$ particle size). The auto-sampler was set at $4{ }^{\circ} \mathrm{C}$. Acetonitrile/ isopropanol/water in a ratio of 100/8/2 $(v / v / v)$ was used as mobile phase, with the flow rate of $1.2 \mathrm{~mL} / \mathrm{min}$. Absorbance of the eluting materials was measured at $250 \mathrm{~nm}$. The Bio-Rad microplate reader from BioRad (Benchmark, Japan) was used to analyze the optical destiny of samples from ELISA and TM activity tests.

\section{Standardization of Danshen and Gegen granules}

Identification and quantification of the major components in Danshen and Gegen granules were performed by Waters HPLC according to our previous study with modifications [22]. The chromatographic separation of the analytes was achieved by an Agilent Eclipse XDBC18 column $(250 \times 4.6 \mathrm{~mm}$ i.d., $5 \mu \mathrm{m}$ particle size $)$. The mobile phase consisting of $0.5 \%$ acetic acid in acetonitrile (solvent A) and $0.5 \%$ acetic acid in water (solvent B) was run with gradient elution at a flow rate of $1 \mathrm{~mL} /$ min. The linear gradient elution was carried out as follows with a total running time of $90 \mathrm{~min}$ : solvent $\mathrm{A}$ was kept at $5 \%$ for the first $5 \mathrm{~min}$, and then increased to $10,17,35$ and $90 \%$ in the next 13, 12, 10 and $30 \mathrm{~min}$, respectively, then returned to $5 \%$ in 5 min and equilibrated for $15 \mathrm{~min}$ before the next injection. HPLC analyses indicated that the marker compounds $(\mu \mathrm{g} / 100 \mathrm{mg}$ granules, mean $\pm \mathrm{SD}, \mathrm{n}=3$ ) for Danshen granules were danshensu (1140.3 \pm 24.6), SAB (821.3 \pm 33.1), PCA $(82.2 \pm 4.6)$, and that for Gegen granules were puerarin $(1314.9 \pm 44.1)$, daidzein $(74.4 \pm 9.4)$ and daidzin $(89.2 \pm 7.2)$, respectively.

\section{Animal treatments}

The dosage of Danshen and Gegen for rats were both $240 \mathrm{mg} / \mathrm{kg} /$ day (twice a day), which were calculated from its respective clinical therapeutic dose recommended by Chinese Pharmacopeia [36]. Since the clinical therapeutic dosage of warfarin in common use was 1-2 mg/day for a person, the equivalent rats dosage was calculated to be $0.2 \mathrm{mg} / \mathrm{kg}$ (human equivalent dosage in rat = human dosage $/ 60 \mathrm{~kg} \times 6.2$ ), once daily [38]. Healthy male SD rats were divided into nine groups $(n=6)$ and each group was treated for five consecutive days with different substance, including Danshen single dose (Danshen $\times 1$ : $240 \mathrm{mg} /$ kg/day), Danshen double dose (Danshen $\times 2: 480 \mathrm{mg} / \mathrm{kg} /$ day), warfarin plus Danshen single dose (War + Danshen $\times 1: 0.2+240 \mathrm{mg} / \mathrm{kg} /$ day), warfarin plus Danshen double dose (War + Danshen $\times 2: 0.2+480 \mathrm{mg} / \mathrm{kg} /$ day), Gegen single dose (Gegen $\times 1$ : $240 \mathrm{mg} / \mathrm{kg} /$ day), Gegen double dose (Gegen $\times 2: 480 \mathrm{mg} / \mathrm{kg} /$ day), warfarin plus Gegen single dose (War + Gegen $\times 1: 0.2+240 \mathrm{mg} / \mathrm{kg} /$ day), warfarin plus Gegen double dose (War + Gegen $\times 2$ : $0.2+480 \mathrm{mg} / \mathrm{kg} /$ day) and warfarin alone (War: $0.2 \mathrm{mg} /$ $\mathrm{kg} /$ day). Danshen/Gegen was given to rats twice daily. In the combination groups, Danshen/Gegen was given to 
rats $2 \mathrm{~h}$ after the oral dosing of warfarin. In addition to the drug-treated groups, $\mathrm{H}_{2} \mathrm{O}$, phenobarbital (PB $60 \mathrm{mg}$ / $\mathrm{kg} /$ day), beta-naphthoflavone (BNF $40 \mathrm{mg} / \mathrm{kg} /$ day) and cyclophosphamide (CPA $40 \mathrm{mg} / \mathrm{kg} /$ day) were also given orally for five consecutive days to rats that formed into one vehicle control and three positive controls (for determining the activity and expressions of CYPs) respectively. Specifically, BNF for CYP1A1, PB for CYP2B1 and CYP2C6 and CPA for CYP2C11, were used to validate the assay. For the determining the activity and expressions of VKOR and TM, warfarin was regarded as the positive control for the assay validation. Two hours after the last dosing, rats were sacrificed by decapitation. Livers, lungs and plasma were obtained from each rat for further treatment and assay.

\section{Tissue sample preparations}

\section{Rat liver microsome ( $R L M)$ preparation}

The rat livers were perfused by saline before being excided surgically on ice and cut into pieces for storage at $-80^{\circ} \mathrm{C}$. The liver microsomes were prepared by series centrifugation as described previously [39]. Briefly, liver samples were thawed and weighed before homogenization medium were added. The tissue was chopped using scissors and homogenized with an automatic homogenizer at $500 \mathrm{rpm}$ (IKA Labortechnik, Staufen, Germany). The resultant homogenates were transferred to clean centrifuge tubes, and centrifuged (Beckman Colter, Inc, Fullerton, CA, USA) at $20,000 \times g$ for $20 \mathrm{~min}$ at $4{ }^{\circ} \mathrm{C}$. The supernatant was collected and further centrifuged at $100,000 \times g$ for $1 \mathrm{~h}$ under $4{ }^{\circ} \mathrm{C}$ by the L8-70 Beckman ultracentrifuge. The obtained microsomal pellet was re-suspended with homogenization medium and stored at $-80^{\circ} \mathrm{C}$. Protein concentrations of the prepared liver microsomes were determined by the BioRad protein assay kit (Bio-Rad Pacific Ltd, Hong Kong) and analyzed by the micro-plate reader (Benchmark, Japan) [40].

\section{Extraction of TM from rat lungs}

Rat lungs were perfused by saline before being excided surgically on ice and cut into pieces for storage at $-80^{\circ} \mathrm{C}$. Pieces of lung were then homogenized in a glass tissue grinder of $50 \mathrm{~mL}$ at $4{ }^{\circ} \mathrm{C}$. Centrifuge was performed at $30,000 \times g$ for $40 \mathrm{~min}$ at $4{ }^{\circ} \mathrm{C}$ to get the pellet, which was re-suspended in $250 \mathrm{~mL}$ buffer $(0.25 \mathrm{M}$ sucrose, $0.02 \mathrm{M}$ Tris- $\mathrm{HCl}$ and $1 \mathrm{mM}$ benzamidine- $\mathrm{HCl}, \mathrm{pH} 7.5$ ), homogenized, and centrifuged again as described above. The TM was finally extracted from the pellet by homogenization in $0.25 \mathrm{M}$ sucrose, $0.02 \mathrm{M}$ Tris- $\mathrm{HCl}, 1 \mathrm{mM}$ benzamidine- $\mathrm{HCl}$, and $0.5 \%(v / v)$ Triton X-100, pH 7.5. This process was repeated three times and TM activity was assessed in the resulting extract [41]. The protein concentration of the extract was measured with Bio-Rad protein assay kit and adjusted to $100 \mathrm{ng} / \mathrm{mL}$.

\section{Methods for pharmacokinetic studies}

CYP activities, mRNA and protein expressions in rat liver

Rat liver microsomal activities for mono-hydroxylation of warfarin

The activities of rat liver microsomes for metabolizing warfarin were detected according to methods from our previous study [22]. A typical incubation $(100 \mu \mathrm{L})$ contained $50 \mathrm{mM}$ Tris- $\mathrm{HCl}$ buffer (pH 7.4), $10 \mathrm{mM} \mathrm{MgCl}_{2}$, $1.0 \mathrm{mg} / \mathrm{mL}$ microsomal protein, and racemic-, $R$ - or $S$-warfarin as substrate respectively $(5 \mu \mathrm{M}$ for $R$ - and $S$-warfarin, $10 \mu \mathrm{M}$ for racemic warfarin). The mixture was pre-warmed in a $37{ }^{\circ} \mathrm{C}$ water bath with gentle shaking for $10 \mathrm{~min}$ before addition of NADPH (final concentration of $1.0 \mathrm{mM}$ ) into the mixture to initiate the reaction. About $0.1 \mathrm{~mL}$ ice-chilled acetonitrile containing internal standard $(2.0 \mu \mathrm{g} / \mathrm{mL}$ of diclofenac sodium $)$ was added and incubated for another $30 \mathrm{~min}$. After the mixture centrifugation, the supernatant was subjected to $\mathrm{LC} /$ MS/MS to compare the mono-hydroxywarfarin metabolites (4'-, 6-, 7-, 8- and 10-hydroxywarfarin) among different treatment groups. The activities of CYPs could be expressed as the amount of mono-hydroxywarfarin metabolites formed.

\section{CYP mRNA expression}

Approximately $30 \mathrm{mg}$ of rat livers were homogenized, and RNA was isolated with the Qiagen RNA extraction kit (Valencia, CA, USA). The quality of RNA was evaluated by measuring the $260 / 280$ ratio ('1.9) with an ultraviolet light spectrophotometer (Shimadzu, Japan). The sequence of the sense and antisense primers for rat CYP1A1 (FP: CCAAACGAGTTCCGGCCT; RP: TGCC CAAACCAAAGAGAATGA) [42], CYP2B1 (FP:AACCC TTGATGACCGCAGTAAA; RP: TGTGGTACTCCAAT AGGGACAAGATC) [42], CYP2C6 (FP: ATAAGACGCT TTACCCTCAC; RP: GATTTTCCTGCTTCCACTTA) [43], CYP2C11 (FP: TGCCCCCTTTTTACGAGGCT; RP: GGAACAGATGACTCTGAATTCT) [44] and GAPDH (FP: CAAGGTCATCCATGACAACTTTG; RP: GGGCC ATCCACAGTCTTCTG) [42] gene were designed as described previously. The reaction mixture system (final volume $20 \mu \mathrm{L}$ ) was prepared as follow: 4 units multiscribe reverse transcriptase, $1 \times \mathrm{RT}$ buffer, $1 \mathrm{mM}$ random hexamer primers, $0.5 \mathrm{mM}$ each of dATP, dGTP, $\mathrm{dCTP}$ and $\mathrm{dTTP}$, and $10 \mathrm{~mL}$ total mRNA extract. The PCR involved an initiating heating for $10 \mathrm{~min}$ at $95{ }^{\circ} \mathrm{C}$, 40 cycles consisting of $10 \mathrm{~s}$ at $95^{\circ} \mathrm{C}, 20 \mathrm{~s}$ at $60{ }^{\circ} \mathrm{C}$, and a final extension step of $30 \mathrm{~s}$ at $72{ }^{\circ} \mathrm{C}$. The fold change of target gene expression level in different drug treatment groups (after correction with the level of GAPDH) 
was determined by the following equation: Fold change $=2^{-\Delta(\Delta \mathrm{Ct})}$, where $\Delta \mathrm{Ct}=\mathrm{Ct}($ target $)-\mathrm{Ct}(\mathrm{GAPDH})$ and $\Delta(\Delta \mathrm{Ct})=\Delta \mathrm{Ct}($ treated $)-\Delta \mathrm{Ct}($ vehicle control $)$ [22]. The Ct (cycle threshold) in the equation was defined as the number of cycles required for the fluorescent signal to cross the threshold.

\section{CYP protein expression}

The levels of CYP1A1, 2B1/2, 2C6, 2C11 and GAPDH proteins in rat liver microsomes obtained from different treatment groups were determined by Western blotting. Sodium dodecyl sulfate (SDS)-PAGE was performed by a Mini-Protean II system (Bio-Rad) as described previously [45]. After denaturing with sample buffer, rat liver microsomal proteins were separated in a $10 \%(w / v)$ SDS-polyacrylamide gel and blotted onto a PVDF membrane (Immobilon transfer membrane, Millipore, Billerica, MA, USA). The membrane was blocked in $5 \%$ defatted milk which was then incubated with the primary and secondary antibodies (horseradish peroxidase labeled anti-mouse or anti-rabbit IgG). The membrane was then immersed in the enhanced chemiluminescence solution (Millipore, Billerica, MA, USA) for $60 \mathrm{~s}$. Digital chemiluminescence images were captured and analyzed by FluorChem Q Imaging System (Alpha Innotech Corporation, Santa Clara, CA, USA).

\section{Methods for pharmacodynamic studies VKOR activity, mRNA and protein expression in rat livers VKOR activity}

Rat liver microsomes of different treatment groups were rinsed and re-suspended in the $0.02 \mathrm{M}$ Tris- $\mathrm{HCl}$ buffer ( $\mathrm{pH}$ 7.4) to obtain a microsomal protein concentration of $5 \mathrm{mg} / \mathrm{mL} 0.02 \mathrm{~mL}$ of this microsomal suspension was mixed with $0.071 \mathrm{~mL}$ of the $0.02 \mathrm{M}$ Tris- $\mathrm{HCl}$ buffered solution ( $\mathrm{pH} 7.4)$. The mixture was pre-incubated for $3 \mathrm{~min}$ at $30{ }^{\circ} \mathrm{C}$. Tris- $\mathrm{HCl}$ buffered solution $(\mathrm{pH} \mathrm{7.4,}$ $2 \mu \mathrm{L} 0.02 \mathrm{M}$ ) containing 0.1 M DTT (Sigma-Aldrich, St. Louis, MO, USA) were added, mixed and incubated for $5 \mathrm{~min}$ at $30^{\circ} \mathrm{C}$. Synthesized VKO $(10 \mathrm{nM})$ in $2 \mu \mathrm{L}$ of isopropanol was also added and subsequently incubated for $60 \mathrm{~min}$ at $30{ }^{\circ} \mathrm{C}$. The reaction was stopped by the addition of $0.1 \mathrm{~mL}$ of ice-chilled isopropanol. Tocopheryl acetate (2.5 $\mu$ g; Sigma-Aldrich, St. Louis, MO, USA) in $0.2 \mathrm{~mL}$ of hexane was added as the internal standard. After vortex for $1 \mathrm{~min}$, the mixture was centrifuged at $15,000 \times g$ for $5 \mathrm{~min}$. The hexane phase was evaporated to dryness with nitrogen [39]. The residue was dissolved in $150 \mu \mathrm{L}$ mixed buffer containing acetonitrile/ isopropanol/water $(100 / 8 / 2: v / v / v)$, and $10 \mu \mathrm{L}$ was analyzed by HPLC. The amount of vitamin $\mathrm{K}_{1}$ formed was determined from the peak height ratio between vitamin $\mathrm{K}_{1} /$ internal standard and a calibration graph. VKOR activity was expressed as the amount of vitamin $K_{1}$ formed.

\section{VKOR MRNA and protein expression}

The sequence of the sense and antisense primers for rat VKOR gene (VKORC1) used in RT-PCR was designed as described previously [46]. RT-PCR procedures for detecting mRNA expression of VKORC1 were same as that described for CYP mRNA expression. VKOR protein expression detection was conducted with the same operations for CYP protein expression.

\section{TM activity, mRNA and protein expression in rat lung TM activity}

The ability of TM to accelerate protein $C$ activation by thrombin was tested by a chromogenic assay as follow: $0.5 \mathrm{M}$ of purified protein $\mathrm{C}$ (Stago) in $100 \mu \mathrm{L}$ of buffer was activated by $10 \mathrm{nM}$ (1 NIH unit) of human thrombin (Sigma-Aldrich, St. Louis, MO, USA) in $10 \mu \mathrm{L}$ of buffer in the presence of $5 \mathrm{mM}$ calcium, $3 \mathrm{mg} / \mathrm{mL}$ of bovine serum albumin and of $50 \mu \mathrm{L}$ of lung extracts from different substance treated groups. The final volume was $200 \mu \mathrm{L}$. Incubation of the mixture lasted $30 \mathrm{~min}$ at $37^{\circ} \mathrm{C}$. The activation phase was stopped by adding 2 units of hirudin. The hydrolytic activity of the activated protein C (APC) thus generated was assessed by spectrophotometric measurement at $405 \mathrm{~nm}$ of the rate of hydrolysis of D-Phe-Pip-Arg-pNA-2 HCl, that is, S-2238. For this purpose, $800 \mu \mathrm{L}$ of Tris- $\mathrm{HCl}$ buffer, $\mathrm{pH} 7.5$, containing $0.1 \mathrm{mM}$ of S-2238 was added to the mixture (final volume: $1 \mathrm{~mL}$ ). The changes in optical density per minute were converted into units of APC formed by referring to a standard curve constructed with concentrations of 20, 40, 80, 160 and $320 \mathrm{n}$ of standard APC (Stago). The activity of TM could be expressed as the amount of APC formed during incubation [47].

\section{TM $m R N A$ and protein expression}

TM mRNA and protein (extracted from rat lung) expression were detected as that described for CYP. The sequence of the sense and antisense primers for rat TM used in RT-PCR was designed as described previously [48].

\section{sTM plasma concentration analysis}

After the animal treatment described previously, blood was collected using $3.8 \%$ sodium citrate (sodium citrate: blood $=1: 9$ ) as an anticoagulant. Plasma was obtained by centrifuging the blood at $15,000 \times g$ for $3 \mathrm{~min}$. The plasma samples were frozen and stored at $-80{ }^{\circ} \mathrm{C}$ until the assay. An enzyme-linked immunosorbent assay (ELISA) was used to measure the plasma concentration of sTM. Standard STM was series diluted to make a calibration 
curve. The concentration of STM was determined from the optical density of each sample at $450 \mathrm{~nm}$ against a calibration graph.

\section{Statistical analysis}

Data were expressed as the mean \pm SD. Differences between two groups were analyzed by an unpaired student's $t$ test. Differences between groups for continuous variables were evaluated by one way ANOVA with post hoc Tukey (when variances were equal according to Levene's test) or Games-Howell test (when variances were not equal according to Levene's test) [49]. $P$ value less than 0.05 was considered as statistically significant.

\section{Results}

Pharmacokinetic mechanisms of warfarin-Gegen interaction

Gegen induced the activities and mRNA expressions of different CYPs in rat liver

Induction on CYP activities for warfarin metabolism When $R$-warfarin was used as the substrate $(5 \mu \mathrm{M})$, the formation of all five mono-hydroxylated warfarin metabolites in the Gegen $\times 1$ and Gegen $\times 2$ groups increased significantly by $19-31 \%(P=0.03)$ and $24-30 \%(P=0.03)$, respectively, relative to the vehicle control group. Compared with the combined amount of all five mono-hydroxylated warfarin metabolites formed in the warfarin-alone group, there were significant increases in both of the combination groups (i.e., War + Gegen $\times 1$ and War + Gegen $\times 2$ ) of $19-49 \%(P=0.02)$ and $22-49 \%(P=0.03)$, respectively. No significant differences were observed in the amounts of the mono-hydroxylated metabolites formed between the vehicle control and Danshen groups. In the positive control groups, the formation of 7- and 8-hydroxylated warfarin increased by $281 \%(P<0.001)$ and $242 \%(P<0.001)$ when the animals were treated with $\mathrm{PB}$ and $\mathrm{BNF}$ (positive controls for the activities of rat CYP2C6 and CYP1A1, respectively, contributing to the formation of 7- and 8-hydroxylated warfarin) [22], respectively, compared with the results of the vehicle control group (Fig. 1).

When $S$-warfarin was used as a substrate $(5 \mu \mathrm{M})$, the formation of the three detectable mono-hydroxylated warfarin metabolites (i.e., 4'-, 6- and 7-hydroxylated warfarin) increased significantly by $14-16 \%(P=0.04)$ and $16-19 \%$ $(P=0.03)$ in the Gegen $\times 1$ and Gegen $\times 2$ groups, respectively, compared with the vehicle control group. Compared with the combined amount of the 4'-, 6- and 7-monohydroxylated warfarin metabolites formed in the warfarinalone group, we observed significant increases of $17-19 \%$ $(P=0.04)$ and $17-22 \%(P=0.03)$ in the formation of these metabolites in the Gegen $\times 1$ and Gegen $\times 2$ groups, respectively. No inductive effects were observed in the Danshentreated groups based on a comparison of the warfarin metabolites formed in this group with those in the vehicle control group. In the positive control groups, the formation of 7-hydroxywarfarin increased by $237 \%(P<0.001)$ when the rats were treated with $\mathrm{PB}$ (positive controls for rat CYP2C6, contributing to the formation of 7-hydroxywarfarin) compared with the vehicle control group (Fig. 2).

When racemic warfarin was used as the substrate (10 $\mu \mathrm{M}$ containing $5 \mu \mathrm{M}$ of the $R$ - and $S$-enantiomers) there were significant increases of $21-28 \%(P=0.03)$ and $24-39 \%(P=0.02)$ in the formation of the $4^{\prime}-, 6_{-}, 7-$, 8 - and 10-hydroxywarfarin metabolites in the Gegen $\times 1$ and Gegen $\times 2$ groups, respectively, compared with the vehicle control group. Compared with the warfarinalone group, the co-administration of Gegen $\times 1$ and Gegen $\times 2$ with warfarin led to significant increases in the formation of all five mono-hydroxylated warfarin metabolites by $21-27 \%(P=0.03)$ and $20-29 \%(P=0.03)$, respectively. No inductive effect was observed when for the warfarin metabolites formed in the Danshen-treated groups based on a comparison of these results with those of the vehicle control group. In the positive control groups, the formation of the 7-and 8-hydroxywarfarin metabolites increased by $251 \%(P<0.001)$ and $209 \%$ $(P<0.001)$ when the rats were treated with PB and BNF, respectively, compared with the vehicle control group (Fig. 3).

Induction of the mRNA expression of CYP1A1, CYP2B1, $C Y P 2 C 6$ and $C Y P 2 C 11$ Compared with the vehicle control group, there were significant increases of $260 \%$ $(P<0.001)$ and $220 \%(P<0.001)$ in the mRNA expression levels of CYP1A1 and CYP2B1 in the Gegen $\times 1$ group, respectively. Similar increases of $250 \%(P<0.001)$ and $290 \%(P<0.001)$ were also observed in the Gegen $\times 2$ group, respectively (Fig. 4). However, these increases were small in size compared with those of the positive control groups. For example, BNF afforded a 8761-fold increase, whereas PB gave a 2812-fold increase. Compared with the mRNA expression ratio of CYP1A1 to CYP2B1 in the warfarin-alone group, there were significant increases $(P<0.001)$ in the counterpart ratios of both combination groups (i.e., War + Gegen $\times 1$ and War + Gegen $\times 2$ ). For example, the former of these two groups (i.e., War + Gegen $\times 1$ ) showed 2.8- and 2.1-fold increases for CYP1A1 and CYP2B1, respectively, whereas the latter group (i.e., War + Gegen $\times 2$ ) showed 4.0- and 1.9-fold increases for CYP1A1 and CYP2B1, respectively. No inductive effects were observed in the mRNA expression levels of CYP1A1 and CYP2B1 when the Danshen-treated group was compared with the vehicle control group.

$\mathrm{PB}$ was used as a positive control to detect the mRNA expression of CYP2C6. Compared with the vehicle control group, there was a significant increase of $420 \%(P<0.001)$ 


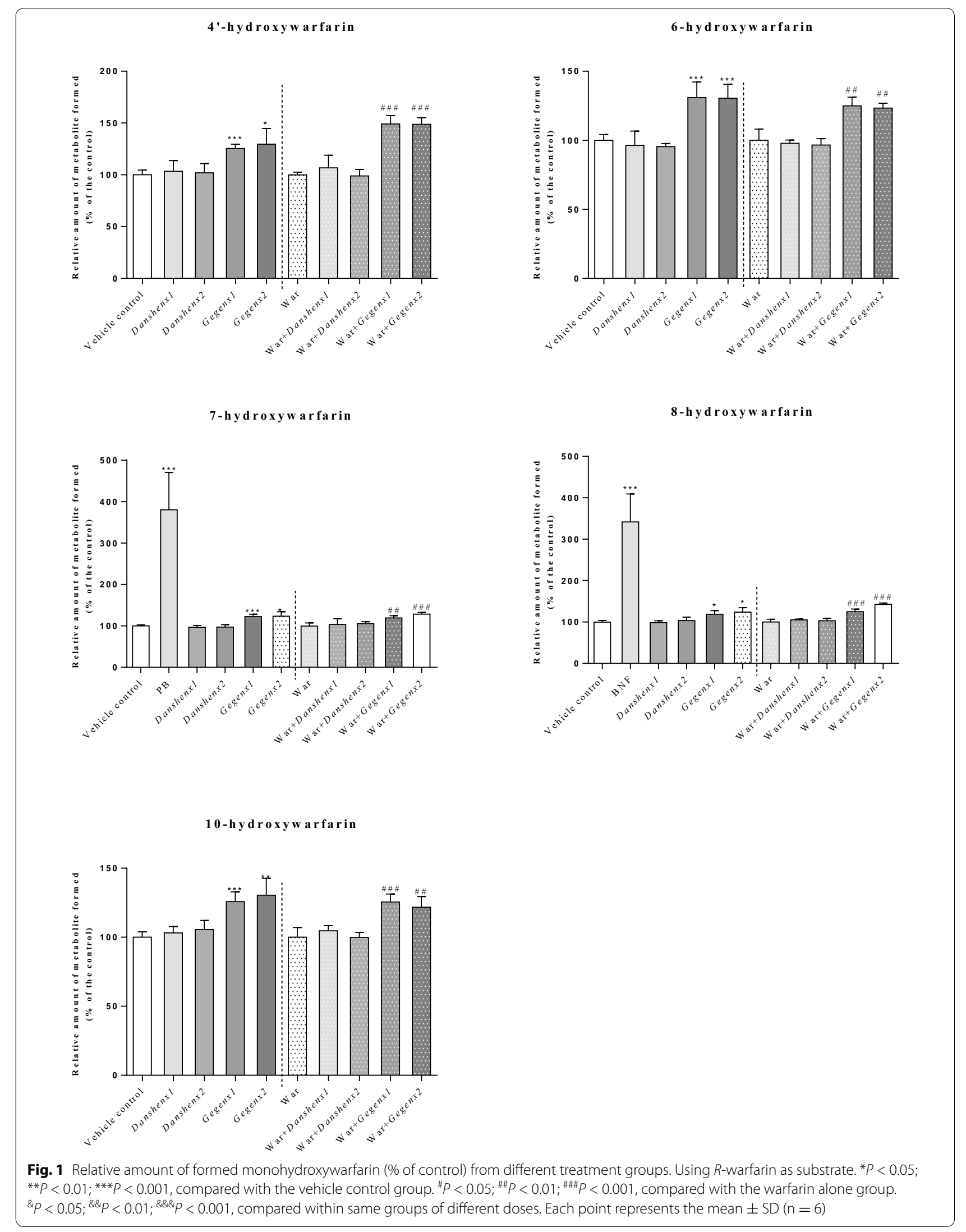




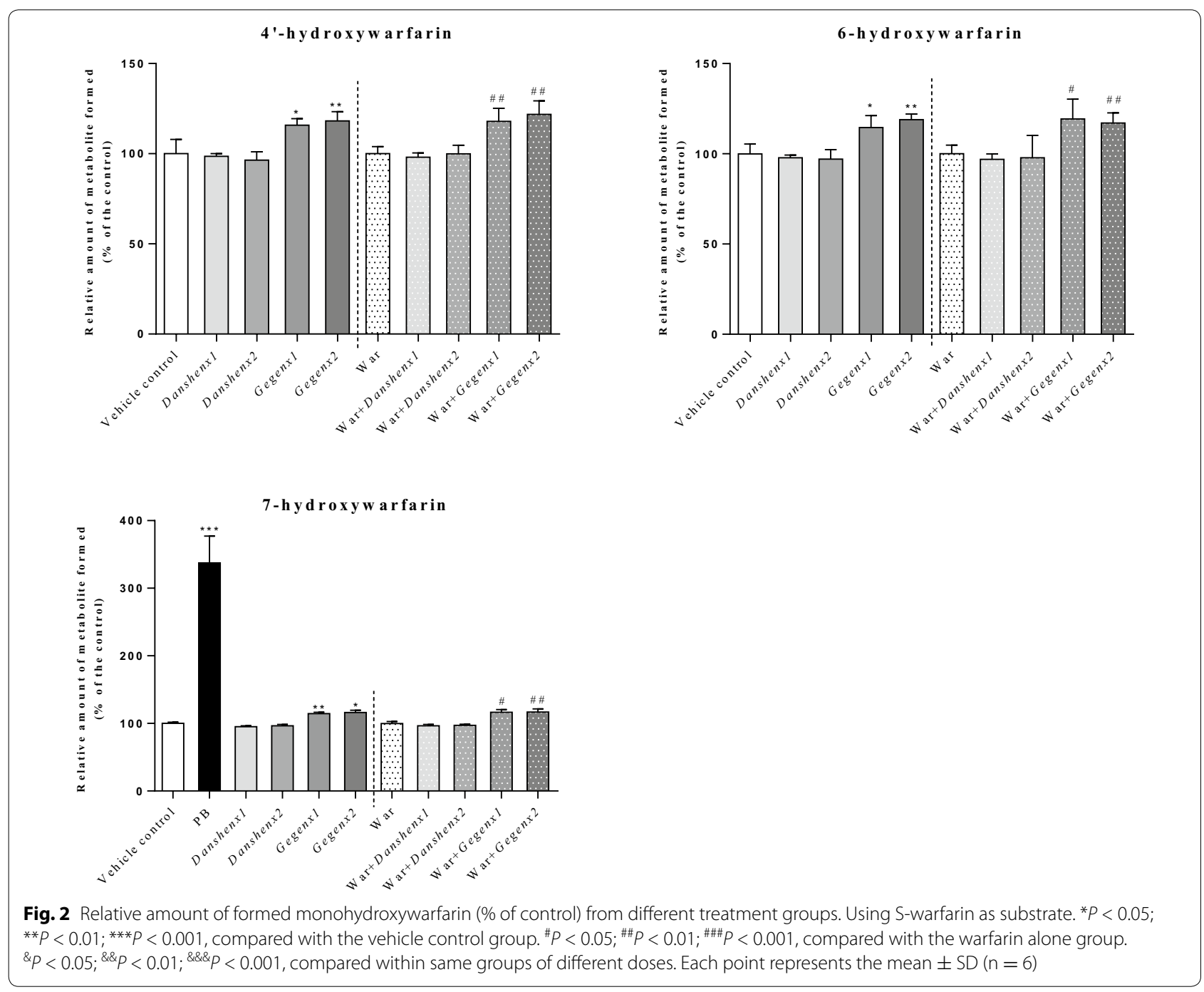

in the mRNA expression ratio of CYP2C6 in the positive control group. Furthermore, the mRNA expression levels of CYP2C6 increased significantly by 1.4- and 1.5-fold in the Gegen $\times 1(P=0.03)$ and Gegen $\times 2(P=0.02)$ groups, respectively, compared with the vehicle control group. A significant 1.4 -fold $(P=0.03)$ increase in the mRNA expression level of CYP2C6 was also observed in both of the Gegen combination groups (i.e., War + Gegen $\times 1$ and War + Gegen $\times 2$ ), compared with the warfarin-alone group. No significant differences were observed in the CYP2C6 mRNA expression ratios between the Gegen $\times 1$ and Gegen $\times 2$ groups. Furthermore, no inductive effects were observed in the mRNA expression level of CYP2C6 for both doses of Danshen compared with the vehicle control group.

In terms of the mRNA expression of CYP2C11, we observed a slight increase of 1.07-fold in the Danshen $\times 1$ group $(P=0.04)$ compared with the vehicle control group. A small increase of $117 \%(P=0.02)$ was also observed in the mRNA expression of CYP2C11 in the War + Gegen $\times 1$ group compared to the warfarin-alone group.

No significant effects on the rat liver CYP protein expressions Changes in the protein expression levels of the target CYP isozymes were determined to be minor compared with those observed for the metabolic activity and mRNA expression levels (Fig. 5). In the Gegen $\times 1$ and Gegen $\times 2$ groups, the expression level of CYP2C6 protein appeared to increase compared with the vehicle control group, but this increase was not statistically significant. No inductive effects were observed in the expression levels of any of the target CYP proteins in the Danshen-treated groups compared with the vehicle control group. In the positive control groups, the expression levels of the CYP1A1, CYP2B1/2B2 and CYP2C6 proteins increased significantly by 6.1- $(P<0.001), 5.6-(P<0.001)$ and 1.7 -fold $(P=0.003)$, respectively, compared with the vehicle control group. 


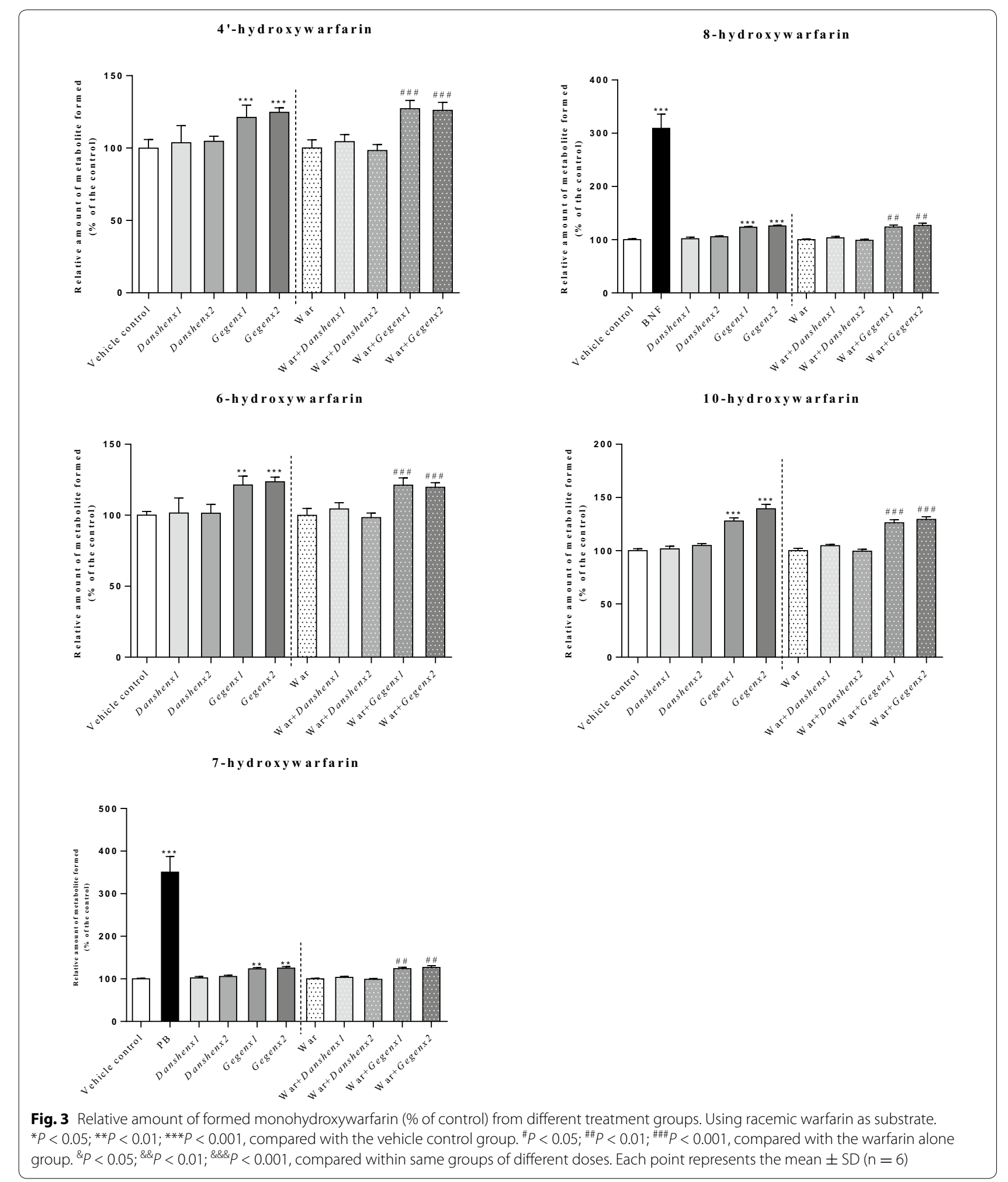



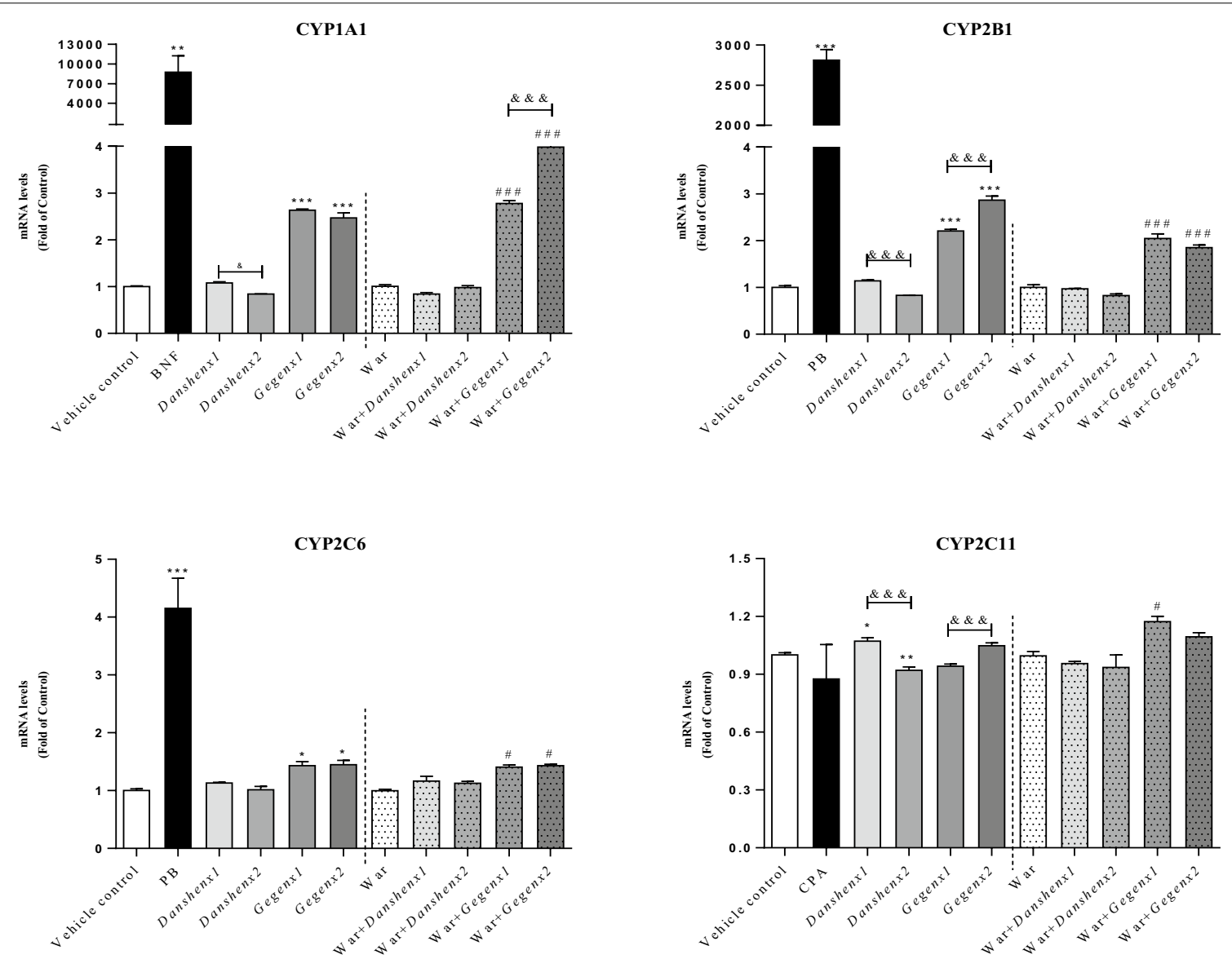

Fig. 4 Rat liver mRNA expression (Fold of Control) for target CYP isoforms from different treatment groups. ${ }^{*} P<0.05$; ${ }^{* *} P<0.01$; ${ }^{* * *} P<0.001$, compared with the vehicle control group. ${ }^{\#} P<0.05 ;{ }^{\# \#} P<0.01 ;{ }^{\# \#} P<0.001$, compared with the warfarin alone group. ${ }^{\&} P<0.05 ;{ }^{\& \&} P<0.01 ;$; \&\& $P<0.001$, compared within same groups of different doses. Each point represents the mean $\pm S D(n=6)$

\section{Pharmacodynamic mechanisms of the warfarin-Gegen interaction}

Gegen led to an increase in the activity, as well as the mRNA and protein expression levels of VKOR in rat liver Induction on VKOR activity

Compared with the vehicle control group, the Danshen $\times 1$ and Danshen $\times 2$ groups showed no significant changes in their VKOR activity. In contrast, there were significant increases of $124.4 \pm 6.3 \%(P<0.001)$ and $131.1 \pm 12.9 \%$ $(P<0.001)$ in the VKOR activities of the Gegen $\times 1$ and Gegen $\times 2$ groups, respectively. Warfarin reduced the activity of VKOR by $52.4 \pm 5.1 \%(P<0.001)$ compared with the vehicle control group, which was consistent with its therapeutic effect. A comparison of the warfarin-alone group with the four different combination groups (i.e., War + Danshen $\times 1$; War + Danshen $\times 2$; War + Gegen $\times 1$; War + Gegen $\times 2$ ) revealed that Danshen had no impact on the VKOR activity during warfarin treatment. In contrast, the co-administration of Gegen with warfarin led to significant increases of $35.9 \pm 4.9 \%(P<0.001)$ and $36.2 \pm 6.9 \%$
$(P<0.001)$ in the VKOR activities of the War + Gegen $\times 1$ and War + Gegen $\times 2$ groups, respectively. However, it was not possible to completely offset the inhibitory activity of warfarin towards VKOR using Gegen (Fig. 6).

\section{Up-regulation in the mRNA and protein expression levels of VKOR}

Compared with the vehicle control group, there were no significant changes in the mRNA and protein expression levels of VKOR in the Danshen $\times 1$ and Danshen $\times 2$ groups. In contrast, there were significant increases of $116.1 \pm 6.6 \%(P<0.001)$ and $123.0 \pm 10.8 \%(P<0.001)$ in the mRNA expression of VKOR in the Gegen $\times 1$ and Gegen $\times 2$ groups, respectively, compared with the vehicle control group. Significant increases of $123.9 \pm 2.9 \%$ $(P=0.002)$ and $127.8 \pm 5.7 \%(P=0.002)$ were also observed in the expression levels of the VKOR protein in the Gegen $\times 1$ and Gegen $\times 2$ groups, respectively, compared with the vehicle control group. Warfarin led to significant reductions of $43.7 \pm 13.9 \%(P<0.001)$ and 


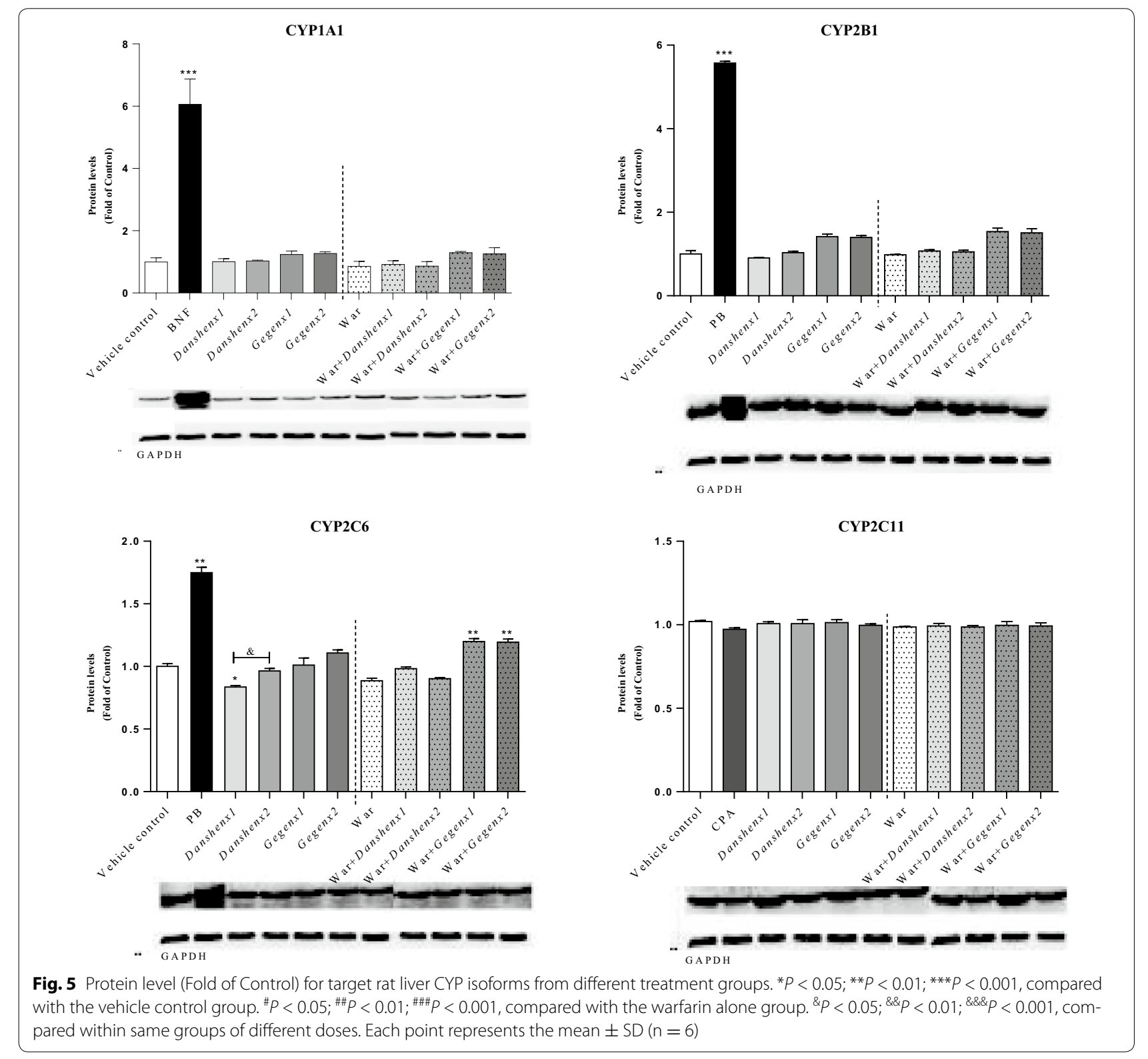

$71.6 \pm 11.4 \%(P=0.004)$ in the mRNA and protein expression levels of VKOR, respectively compared with the vehicle control group. Compared with the mRNA and protein expression levels of VKOR in the warfarin-alone group, there were significant increases $(P<0.001)$ of $27 \%$ (mRNA expression) and $25 \%$ (protein expression) in the corresponding Gegen combination groups, respectively. However, the co-administration of Danshen with warfarin had no discernible impact of the mRNA or protein expression of VKOR (Fig. 7).
Gegen reduced the activity, as well as the mRNA and protein expression levels of TM in rat lung Inhibition of the TM activity

Compared with the vehicle control group, there were no significant changes in the TM activities of the groups treated with Danshen or Gegen, although there did appear to be a decrease in the TM activities of the Gegen $\times 1$ and Gegen $\times 2$ groups. Warfarin led to a significant increase of $125.7 \pm 4.2 \%(P<0.001)$ in the TM activity compared with the vehicle control group. A 


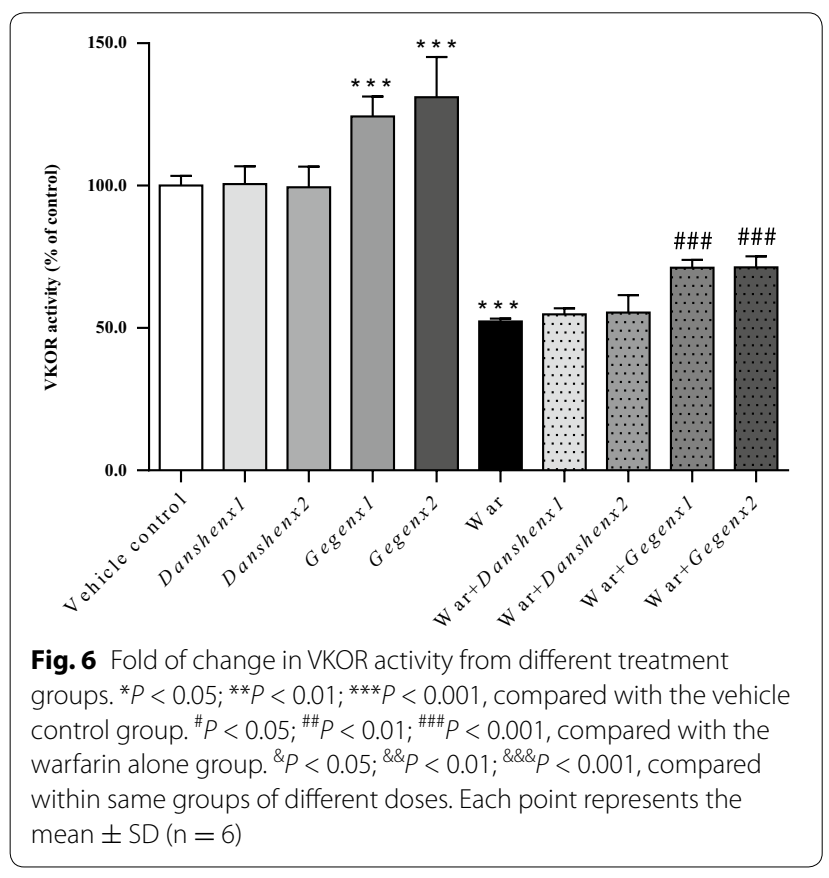

comparison of the warfarin-alone group with the combination groups (i.e., War + Danshen $\times 1$; War + Danshen $\times 2$; War + Gegen $\times 1$; War + Gegen $\times 2$ ) showed that Danshen did not affect the activity of TM during warfarin treatment. In contrast, the co-administrating of Gegen with warfarin led to significant decreases of $83.1 \pm 3.2 \%(P=0.003)$ and $80.6 \pm 2.9 \%(P=0.003)$ in the TM activities of the War + Gegen $\times 1$ and
War + Gegen $\times 2$ groups, respectively. Gegen could therefore be used to offset the induction effect of warfarin towards TM activity (Fig. 8).

\section{Down-regulation of the mRNA and protein expression levels of TM}

Compared with the vehicle control group, no significant change was observed in the expression of the TM protein in the Danshen group, but we did observe an increase of almost $125 \%(P=0.02)$ in the mRNA expression of TM. In contrast, significant decreases of $66.3 \pm 1.5 \%(P=0.03)$ and $63.3 \pm 7.5 \%(P=0.03)$ were observed in the mRNA expression levels of TM in the Gegen $\times 1$ and Gegen $\times 2$ groups, respectively, compared with the vehicle control group. We also observed significant decreases of $67.6 \pm 12.5 \%(P=0.03)$ and $63.3 \pm 7.5 \%(P=0.03)$ in the expression levels of the TM protein in the Gegen $\times 1$ and Gegen $\times 2$ groups, respectively, compared with the vehicle control group. Significant increases of $141.9 \pm 17.8 \%(P=0.003)$ and $158.6 \pm 8.2 \%(P=0.002)$ were observed in the mRNA and protein expression levels of TM in the warfarinalone group compared with the vehicle control group. Compared with the mRNA and protein expression levels of TM in the warfarin-alone group, we observed decreases of nearly $25 \%(P=0.03$, mRNA expression $)$ and $12 \%(P=0.04$, protein expression), respectively, in the Gegen combination groups. Notably, the co-administration of Danshen with warfarin had no discernible impact on the mRNA or protein expression levels of TM compared with the warfarin-alone group (Fig. 9).

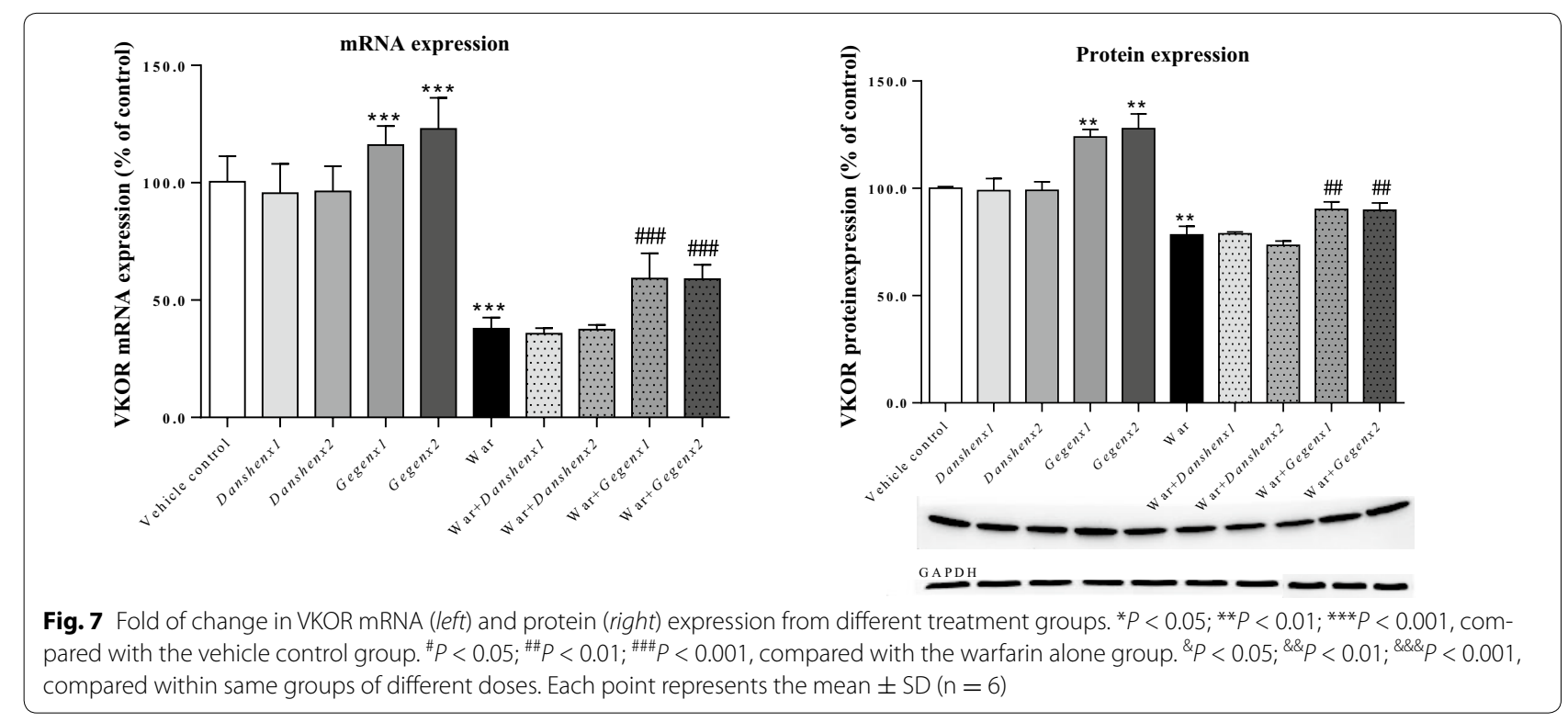




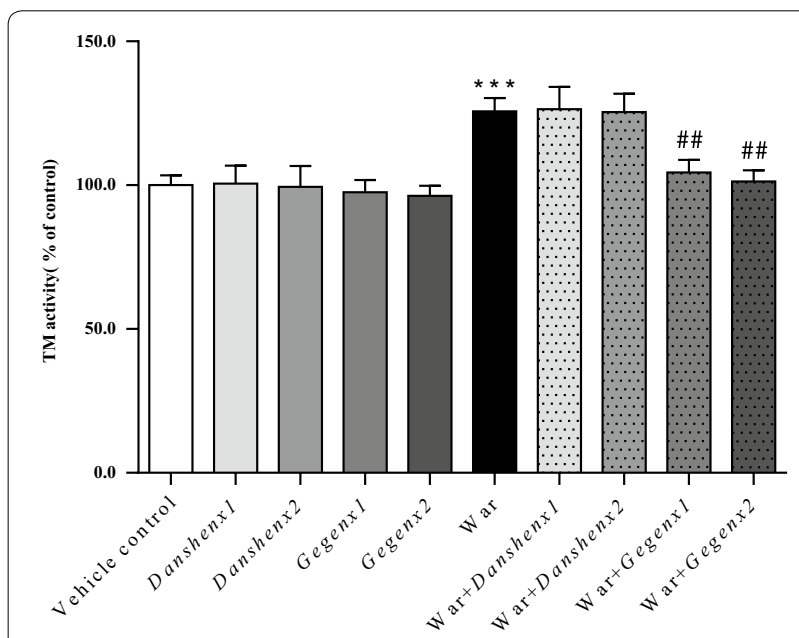

Fig. 8 Fold of change in TM activity from different treatment groups. ${ }^{*} P<0.05$; ${ }^{* *} P<0.01$; ${ }^{* *} P<0.001$, compared with the vehicle control group. ${ }^{\#} P<0.05$; ${ }^{\#} P<0.01$; ${ }^{\# \#} P<0.001$, compared with the warfarin alone group. $\& P<0.05 ; \& \&<0.01$; \&\&\& $P<0.001$, compared within same groups of different doses. Each point represents the mean \pm SD $(n=6)$

\section{Gegen led to a decrease in the plasma concentration of sTM}

Compared with the vehicle control group, there were no discernible changes in the plasma concentration of sTM in the Danshen $\times 1$ and Danshen $\times 2$ groups. In contrast, significant decreases of $86.3 \pm 1.5 \%(P=0.01)$ and $86.5 \pm 1.8 \%(P=0.01)$ were observed in the plasma concentrations of sTM in the Gegen $\times 1$ and Gegen $\times 2$ groups, respectively. Warfarin led to an increase in the plasma concentration of sTM to $112.0 \pm 3.2 \%(P=0.03)$ compared with the vehicle control group. A comparison of the warfarin-alone group with the different combination groups (i.e., War + Danshen $\times 1$; War + Danshen $\times 2$; War + Gegen $\times 1$; War + Gegen $\times 2$ ) showed that Danshen had no discernible impact on the plasma concentration of sTM during warfarin treatment. In contrast, significant decreases of $11.4 \pm 1.7 \%(P=0.03)$ and $10.2 \pm 1.5 \%$ $(P=0.03)$ were observed in the plasma concentrations of sTM for the War + Gegen $\times 1$ and War + Gegen $\times 2$ groups, respectively (Fig. 10).

\section{Discussion}

Danshen and Gegen elicit their effects by improving microcirculation and inhibiting platelet aggregation [24, 32], whereas warfarin exerts its anticoagulant effect by inhibiting the activity of VKOR and inducing TM.

In the healthy Sprague-Dawley rats used in the current study, Gegen rather than Danshen interacted with warfarin to offset its anticoagulant effects. In the Gegenwarfarin interaction, Gegen could induce the phase I metabolism of warfarin in the liver by increasing the activities and mRNA expression levels of the different CYP isozymes, as well as inducing the activity and expression levels of VKOR and inhibiting those of TM. The results of our previous study showed that the administration of a DFG-warfarin combination led to a reduction in the warfarin plasma concentration and PT time

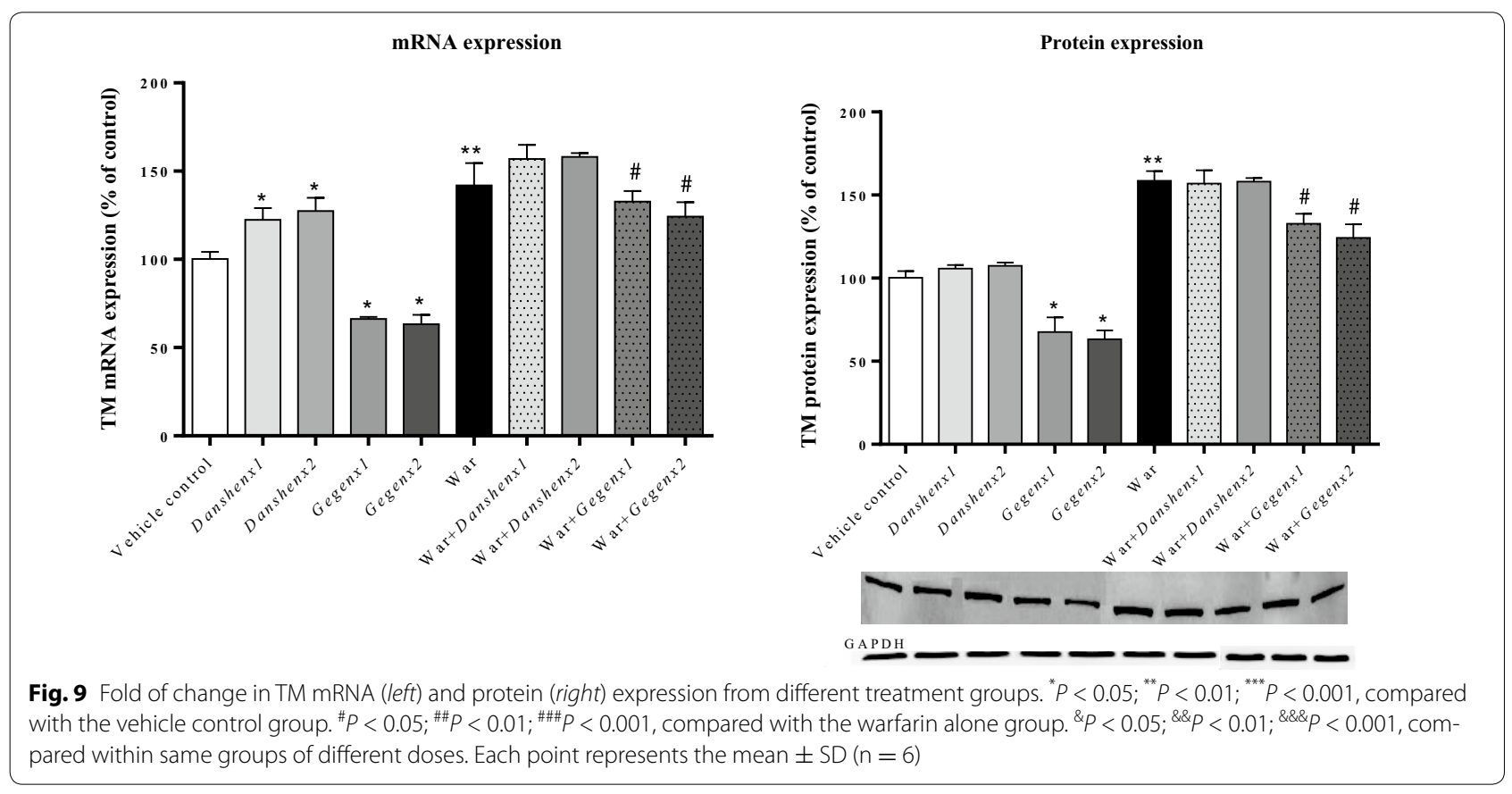




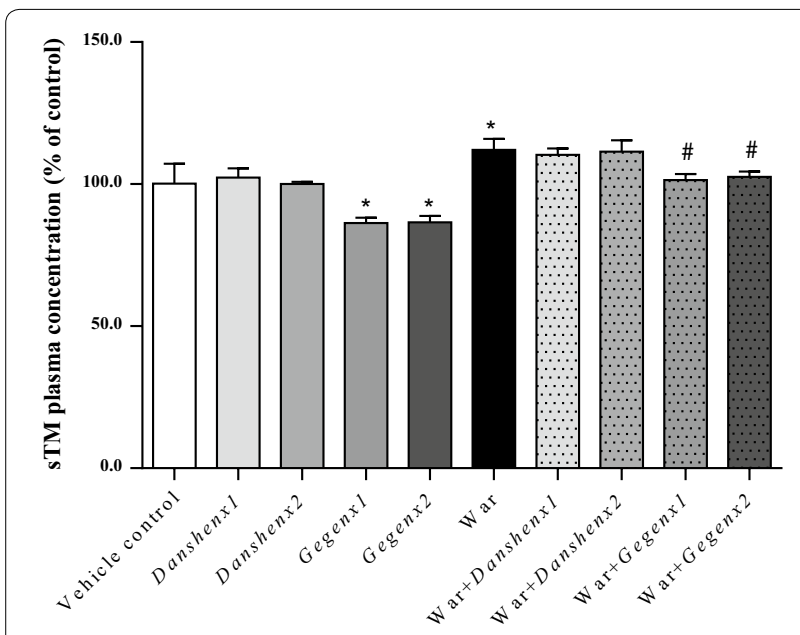

Fig. 10 Fold of change in STM plasma concentration from different treatment groups. ${ }^{*} P<0.05 ;{ }^{* *} P<0.01 ;{ }^{* * *} P<0.001$, compared with the vehicle control group. ${ }^{\#} P<0.05 ;{ }^{\# \#} P<0.01 ;{ }^{\# \#} P<0.001$, compared with the warfarin alone group. ${ }^{\&} p<0.05$; \& $p<0.01$; \&\& $p<0.001$, compared within same groups of different doses. Each point represents the mean $\pm S D(n=6)$

of rats [23, 32]. Taken together with the results of the current study, it seems clear that these effects could be attributed to the Gegen present in DFG.

Although there were no clinical reports in the literature pertaining to the interactions between Gegen and warfarin, the results of several case reports indicated that Danshen can interact with warfarin in humans [20-22]. However, these reports are inconsistent with our current findings. This discrepancy could be caused by several different factors, including (1) the use of different sources and preparations of Danshen (e.g., differences in the quality of the herbal medicines/contamination profiles); (2) a lack of adequate information in the documented case report (e.g., only one case report failed to infer a causal relationship); and (3) differences in the nature of the animals used in the different studies (e.g., rats versus humans). CYP enzymes represent some of the most highly conserved entities among different species, with relatively small differences in the primary amino acid sequences of the CYP enzymes across different species [50,51]. Human CYP2C9, CYP2C19, CYP1A1 and CYP1A2 play important roles in warfarin metabolism, especially CYP2C9 [5], whereas the corresponding enzymes in rats are CYP2C11, CYP2C6, CYP1A1 and CYP2B1 (Fig. 11) [52]. Rat CYP1A1 shows a high level of conservation among species with greater than $80 \%$ sequence identity compared with the corresponding enzyme in humans $[50,51]$. The 6-, 7- and 8-mono-hydroxylated warfarin metabolites are formed by the CYP1A1 enzymes in rats and humans [50, 51]. Furthermore, gene sequence similarities of $74-80 \%$ were reported for the CYP2C11 and CYP2C6 enzymes in rats compared with the human enzymes belonging to the
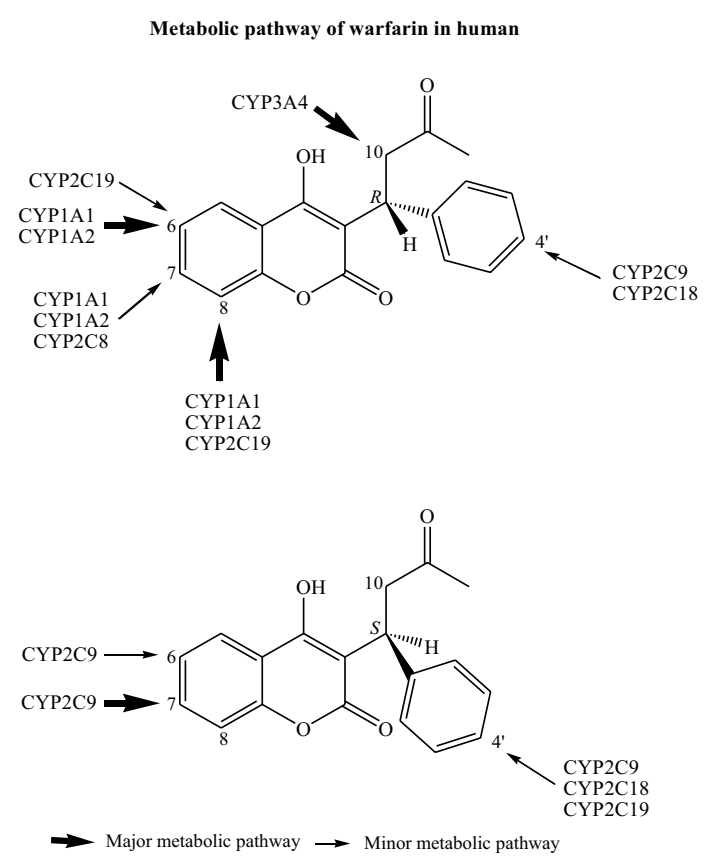

Fig. 11 CYPs involved in warfarin metabolism in human and rat
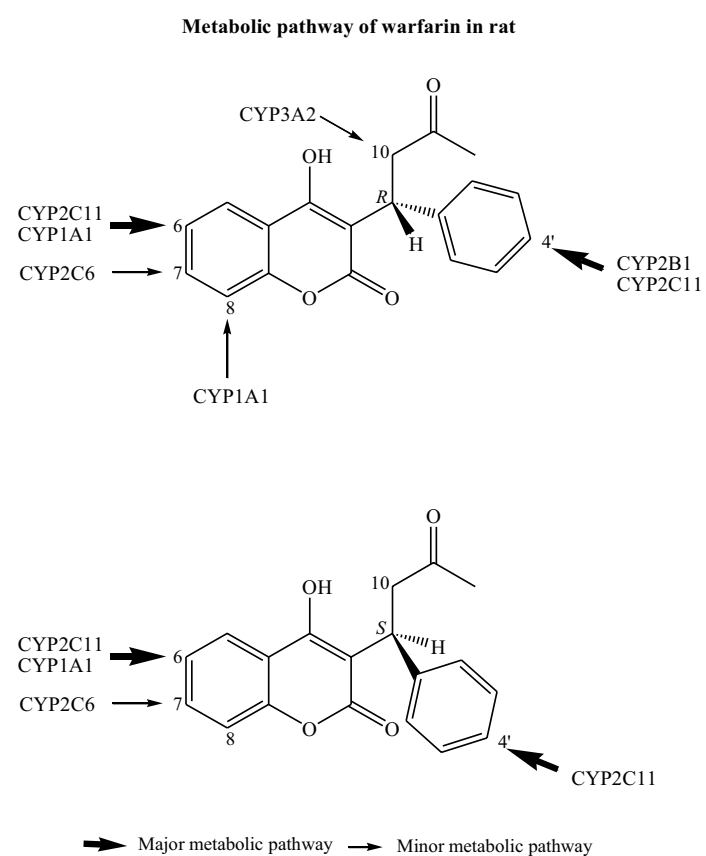
CYP2C subfamily (mainly CYP2C9 and 2C19) [50, 51]. The 4'-, 6- and 7-mono-hydroxylated warfarin metabolites are mainly formed by CYP2C11 and CYP2C6 in rats. In humans, however, these metabolites are formed by CYP2C9, CYP2C19 and CYP2C18. Notably, a genetic similarity of $78 \%$ was reported between the rat and human CYP2B1 enzymes, which are responsible for the formation of 4'-mono-hydroxylated warfarin [50, 51]. Based on the details provided above, CYP2C11, CYP2C6, CYP1A1 and CYP2B1 were selected in the current study to investigate warfarin-related interactions in a rat model. Although these isoforms are expressed in several different species, a high degree of similarity in their gene sequences between rats and human may not automatically result in similar levels of catalytic specificity and activity.

As well as assessing the impact of warfarin on the activities of CYPs, we also investigated the variability in the effects of warfarin in humans caused by polymorphisms in the CYP2C9 and VKORC1 genes [53]. Algorithms that integrate the relevant genetic and physical factors into comprehensive, individualized predictive models were used to predict warfarin dose [54]. Furthermore, physiological-based pharmacokinetic (PBPK) modeling and simulation software, including Simcyp, PK-Sim, GastroPlus and MATLAB Sim-Biology, were recently made available to quantitatively predict the drug/herb-drug interactions of warfarin in humans based on rat data [54].

The results of an in vitro study using HepG2 cells indicated that tanshinones could be used to induce the expression of CYP1A1 and CYP1A2 [55]. The treatment of rats with Danshen, which mainly consists of danshensu, $\mathrm{SAB}$ and tanshinones, led to an increase in the activity and protein expression of CYP1A2. However, the activity of CYP1A2 did no change when rat hepatocytes were treated with danshensu or SAB in isolation [56]. Furthermore, CYP1A-, CYP2C- and CYP3Ainducing agents were found in the ethyl acetate extract, but not in the aqueous extract of Danshen [57]. Taken together, the results of these previous studies indicate that the lipophilic tanshinones in Danshen, rather than the hydrophilic components, were responsible for inducing the activity and enhancing expression of the different CYP isozymes. We found that the major components in Danshen granules were hydrophilic compounds, including danshensu $(1140.3 \pm 24.6 \mu \mathrm{g} / 100 \mathrm{mg}$ granules), SAB (821.3 $\pm 33.1 \mu \mathrm{g} / 100 \mathrm{mg}$ granules) and PCA $(82.2 \pm 4.6 \mu \mathrm{g} / 100 \mathrm{mg}$ granules), which might explain why Danshen showed no effect on the CYP activities or expression levels. This finding is also supported by Yueng's study, where the major tanshinone components rather than the aqueous extract of Danshen showed effects on warfarin hydroxylation in vitro and in vivo [58].
Although paracetamol and sodium dehydroacetate (DHA-S) were reported to interact with warfarin by inhibiting VKOR activity, leading to hemorrhage in SpragueDawley rats, similar studies pertaining to the VKOR activity have never been conducted in context of herb-warfarin interactions $[9,10]$. Regarding the results of previous studies on TM, the treatment of H9c2 cells with DFG led to a 5.36-fold up-regulation in the mRNA expression of TM compared with a control system [16]. Furthermore, SAB led to an 1.25- and 1.8-fold increases in the activity and mRNA expression of TM, respectively, over the control levels in human umbilical vein endothelial cells [15]. In our study, the mRNA expression of TM in the Danshen-treated group was slightly higher than that of the vehicle control group. However, there were no significant differences in the activity and protein expression levels of TM between these two groups. The inconsistencies observed between our own findings and those reported by other researchers could be attributed to differences in the nature of the experiments. For example, SAB was directly loaded onto the cells used in Shi's study at a high concentration $(0.0125-0.5 \mathrm{mg} / \mathrm{mL})$ [15]. However, SAB was reported to be poorly absorbed in animal studies and has an extremely low systemic bioavailability [59]. In our study, although SAB was used as a major component of the Danshen granules, the in vivo effects were very different to those observed in cells because of the poor absorption and bioavailability of SAB. Moreover, the other components in the herbs could also act on the CYP, VKOR and TM enzymes. All of these factors could therefore be considered as potential explanations for the discrepancies observed between the in vitro and in vivo results.

\section{Conclusion}

Gegen, rather than Danshen at the same tested dosage, offsets the anticoagulant effects of warfarin by accelerating the phase I liver metabolism of warfarin, as well as increasing the activity, mRNA and protein expression of VKOR while decreasing those of TM.

\section{Additional file}

Additional file 1. Animal liscence.

\section{Abbreviations}

CYP: liver cytochrome P450; VKOR: vitamin K epoxide reductase; VKO: vitamin K 2, 3-epoxide; VK: vitamin K; TM: thrombomodulin; DGF: Danshen-Gegen Formula; SAB: salvianolic acid B; PB: phenobarbital; BNF: beta-naphthoflavone; CPA: cyclophosphamide; ELISA: enzyme-linked immunosorbent assay.

\section{Authors' contributions}

BKG, ZZh and ZZu conceived and designed the study. BKG and ZZh performed the experiments. BKG, ZZh and ZZu analyzed the data. BKG, ZZh and. ZZu wrote the manuscript. All authors read and approved the final manuscript. 


\section{Acknowledgements}

This work was supported by the Health and Medical Research Fund 6903483 from the Food and Health Bureau, Hong Kong SAR, China.

\section{Competing interests}

The authors declare that they have no competing interests.

Received: 15 January 2015 Accepted: 15 February 2016

Published online: 27 February 2016

\section{References}

1. Ge BK, Zhang Z, Zuo Z. Updates on the clinical evidenced herb-warfarin interactions. Evid Based Complement Alternat Med. 2014;2014:957362. doi:10.1155/2014/957362.

2. Ramsay NA, Kenny MW, Davies G, Patel JP. Complimentary and alternative medicine use among patients starting warfarin. Brit J Haematol. 2005; 130:778-80

3. Ernst E, Pittler MH, Stevinson C, White A. The desktop guide to complementary and alternative medicine. Br J Clin Pharmacol. 2002;54:454.

4. Hirsh J, Dalen JE, Anderson DR, Poller L, Bussey H, Ansell J, Deykin D. Ora anticoagulants: mechanism of action, clinical effectiveness, and optimal therapeutic range. Chest. 2001;119:8s-21s.

5. Kaminsky LS, Zhang ZY. Human P450 metabolism of warfarin. Pharmacol Ther. 1997:73:67-74

6. Guo L, Yamazoe Y. Inhibition of cytochrome P450 by furanocoumarins in grapefruit juice and herbal medicines. Acta Pharmacol Sin. 2004;25:129-36.

7. Foster BC, Foster MS, Vandenhoek S, Krantis A, Budzinski JW, Arnason JT, et al. An in vitro evaluation of human cytochrome P450 3A4 and P-glycoprotein inhibition by garlic. J Pharm Pharm Sci. 2001;4:176-84.

8. Macan H, Uykimpang R, Alconcel M, Takasu J, Razon R, Amagase H, Niihara Y. Aged garlic extract may be safe for patients on warfarin therapy. J Nutr. 2006;136:793-5.

9. Sakaguchi Y, Suga S, Oshida K, Miyamoto-kuramitsu K, Ueda K, Miyamoto Y. Anticoagulant effect of sodium dehydroacetate (DHA-S) in rats. J Appl Toxicol. 2008;28:524-9.

10. Thijssen HH, Soute BA, Vervoort LM, Claessens JG. Paracetamol (Acetaminophen) warfarin interaction: NAPQI, the toxic metabolite of paracetamol, is an inhibitor of enzymes in the vitamin K cycle. Thromb Haemost. 2004;92:797-802.

11. Weiler $\mathrm{H}$, Isermann BH. Thrombomodulin. J Thromb Haemost. 2003;1:1515-24

12. Ikemoto T, Hojo Y, Kondo H, Takahashi N, Hirose M, Nishimura Y, Katsuki T, Shimada K, Kario K. Plasma endoglin as a marker to predict cardiovascular events in patients with chronic coronary artery diseases. Hear Vessel. 2012;27:344-51.

13. Takano S, Kimura S, Ohdama S, Aoki N. Plasma thrombomodulin in health and diseases. Blood. 1990;76:2024-9.

14. Dharmasaroja P, Dharmasaroja PA, Sobhon P. Increased plasma soluble thrombomodulin levels in cardioembolic stroke. Clin Appl Thromb Hem. 2012;18:289-93

15. Shi CS, Huang HC, Wu HL, Kuo CH, Chang BI, Shiao MS, Shi GY. Salvianolic acid $B$ modulates hemostasis properties of human umbilical vein endothelial cells. Thromb Res. 2007;119:769-75.

16. Fong CC, Wei F, Chen Y, Yu WK, Koon CM, Leung PC, Fung KP, Lau BS, Yang MS. Danshen-Gegen decoction exerts proliferative effect on rat cardiac myoblasts H9c2 via MAPK and insulin pathways. J Ethnopharmacol. 2011;138:60-6.

17. Chiu PY, Wong SM, Leung HY, Leong PK, Chen N, Zhou LM, Zuo Z, Lam PY, Ko KM. Long-term treatment with Danshen-Gegen decoction protects the myocardium against ischemia/reperfusion injury via the redox-sensitive protein kinase $\mathrm{C}-\varepsilon / \mathrm{mK}(\mathrm{ATP})$ pathway in rats. Rejuv Res. 2011;14:173-84.

18. Chang Q, Sun L, Zhao RH, Chow MSS, Zuo Z. Simultaneous determination of ten active components in traditional Chinese medicinal products containing both Gegen (Pueraria lobata) and Danshen (Salvia miltiorrhiza) by high-performance liquid chromatography. Phytochem Anal. 2008;19:368-75.
19. Chook P, Tam WY, Chan LT, Qiao M, Cheng KF, Poon YK, Qiao M, Chan LT, Cheung SP, Cheng KF, Fung KP, Tang SL, Lau KM, Koon CM, Leung PC, Celermjer DS, Woo KS. Efficacy and safety of Danshen and Gegen as adjunctive secondary prevention therapy in coronary artery disease. South China J Cardio Vasc Dis. 2011;17:48-52.

20. Chook P, Tam LW, Poon PY, Qiao M, Chan LL, Cheung AS, Cheng KF, Fung KP, Tang SL, Koon CM, Leung PC, Celermjer DS, Woo KS. Danshen and Gegen as cardiovascular tonic in coronary patients: a novel strategy for secondary atherosclerosis prevention. South China J Cardio Vasc Dis. 2005; 12:32.

21. Tam WY, Chook P, Qiao M, Chan LT, Chan TYK, Poon YK, Fung KP, Leung PC, Woo KS. The efficacy and tolerability of adjunctive alternative herbal medicine (Salvia miltiorrhiza and Pueraria lobata) on vascular function and structure in coronary patients. J Altern Complem Med. 2009;15:415-21.

22. Zhang Z, Ge BK, Zhou LM, Lam TN, Zuo Z. Induction of liver cytochrome P450 s by Danshen-Gegen formula is the leading cause for its pharmacokinetic interactions with warfarin. J Ethnopharmacol. 2014;154:672-86.

23. Zhou LM, Wang S, Zhang Z, Lau BS, Fung KP, Leung PC, Zuo Z. Pharmacokinetic and pharmacodynamic interaction of Danshen-Gegen extract with warfarin and aspirin. J Ethnopharmacol. 2012;143:648-55.

24. Cheng TO. Cardiovascular effects of Danshen. Int J Cardiol. 2007;121:9-22.

25. Wang BQ. Salvia miltiorrhiza: chemical and pharmacological review of a medicinal plant. J Med Plants Res. 2010;4:2813-20.

26. Chan TYK. Interaction between warfarin and Danshen (Salvia miltiorrhiza). Ann Pharmacother. 2001;35:501-4.

27. Izzat MB, Yim APC, El-Zufari MH. A taste of Chinese medicine! Ann Thorac Surg. 1998;66:941-2.

28. Tam LS, Chan TYK, Leung WK, Critchley JAJH. Warfarin interactions with Chinese traditional medicines: danshen and methyl salicylate medicated oil. Aust NZ J Med. 1995;25:258.

29. Yu C, Chan J, Sanderson J. Chinese herbs and warfarin potentiation by 'danshen'. J Inter Med. 1997;241:337-9.

30. La ACT, Chan K, Yeung JHK, Woo KS. The effects of Danshen (Salvia miltiorrhiza) on pharmacokinetics and pharmacodynamics of warfarin in rats Eur J Drug Metab Pharmacokinet. 1992;17:257-62.

31. Chu Y, Zhang L, Wang X, Guo J, Guo Z, Ma X. The effect of compound Danshen dripping pills, a Chinese herb medicine, on the pharmacokinetics and pharmacodynamics of warfarin in rats. J Ethnopharmacol. 2011;137:1457-61.

32. Zhang Z, Lam TN, Zuo Z. Radix Puerariae: an overview of its chemistry, pharmacology, pharmacokinetics, and clinical use. J Clin Pharmacol. 2013:53:787-811.

33. Guerra MC, Speroni E, Broccoli M, Cangini M, Pasini P, Minghett $A$, Crespi-Perellino N, Mirasoli M, Cantelli-Forti G, Paolini M. Comparison between Chinese medical herb Pueraria Lobata crude extract and its main isoflavone puerarin antioxidant properties and effects on rat liver CYP-catalysed drug metabolism. Life Sci. 2000;67:2997-3006.

34. Zheng J, Chen B, Jiang B, Zeng L, Tang ZR, Fan L, Zhou HH. The effects of puerarin on CYP2D6 and CYP1A2 activities in vivo. Arch Pharm Res. 2010;33:243-6.

35. Tsai HH, Lin HW, Lu YH, Chen YL, Mahady GB. A review of potential harmful interactions between anticoagulant/antiplatelet agents and Chinese herbal medicines. PLOS ONE. 2013;8:e64255.

36. Chinese-Pharmacopoeia, 2010. Pharmacopoeia of the People's Republic of China Version 2010, vol. 1. Beijing: Chemical Industry Press; 2010.

37. Tishler M, Louis FF, Norman LW. Hydro, oxido and other derivatives of vitamin $K_{1}$ and related compound. J Am Chem Soc. 1940;62:2866-71.

38. Reagan-Shaw S, Nihal M, Ahmad N. Dose translation from animal to human studies revisited. FASEB J. 2008;22:659-61.

39. Wallin R, Martin LF. Warfarin poisoning and vitamin Kantagonism in rat and human liver. Design of a system in vitro that mimics the situation in vivo. Biochem J. 1987;241:389-96.

40. Fong YK, Li CR, Wo SK, Wang S, Zhou L, Zhang L, Lin G, Zuo Z. In vitro and in situ evaluation of herb-drug interactions during intestinal metabolism and absorption of baicalein. J Ethnopharmacol. 2012;141:742-53.

41. Esmon NL, Owen WG, Esmon CT. Isolation of a membrane-bound cofactor for thrombin-catalyzed activation of protein C. J Biol Chem. 1982;257:859-64.

42. Baldwin SJ, Bramhall JL, Ashby CA, Yue L, Murdock PR, Hood SR, Ayrton AD, Clarke SE. Cytochrome P450 gene induction in rats ex vivo assessed 
by quantitative real-time reverse transcriptase-polymerase chain reaction (Taqman). Drug Metab Dispos. 2006;34:1063-9.

43. Hoen PA, Bijsterbosch MK, van Berkel TJ, Vermeulen NP, Commandeur JN. Midazolam is a phenobarbital-like cytochrome p450 inducer in rats. J Pharmacol Exp Ther. 2001;299:921-7.

44. Rahmaniyan M, Patrick K, Bell NH. Characterization of recombinant CYP2C11: a vitamin D 25-hydroxylase and 24-hydroxylase. Am J Physiol Endocrinol Metab. 2005;288:e753-60.

45. Laemmli UK. Cleavage of structural proteins during the assembly of the head of bacteriophage T4. Nature. 1970;227:680-5.

46. Lasseur R, Longin-Sauvageon C, Videmann B, Billeret M, Berny P, Benoit E. Warfarin resistance in a French strain of rats. J Biochem Mol Toxicol. 2005;19:379-85

47. He CJ, Kanfer A. Quantification and modulation of thrombomodulin activity in isolated rat and human glomeruli. Kidney Int. 1992;41:1170-4

48. Yamashita T, Sekiguchi A, Iwasaki Y, Sagara K, Hatano S, linuma H, Aizawa T, Fu LT. Thrombomodulin and tissue factor pathway inhibitor in endocardium of rapidly paced rat atria. Circulation. 2003;108:2450-2.

49. Wong YC, Zuo Z. Brain disposition and catalepsy after intranasal delivery of Loxapine: role of metabolism in PK/PD of intranasal CNS drugs. Pharm Res. 2013;30:2368-84.

50. Martignoni M, Groothuis GMM, De Kanter R. Species differences between mouse, rat, dog, monkey and human CYP-mediated drug metabolism, inhibition and induction. Expert Opin Drug Metab Toxicol. 2006;2:875-94.

51. Fasco MJ, Silkworth JB, Dunbar DA, Kaminsky LS. Rat small intestinal cytochromes probed by warfarin metabolism. Mol Pharmacol. 1992;43:226-33.
52. Soucek P, Gut I. Cytochromes P-450 in rats: structures, functions, properties and relevant human forms. Xenobiotica. 1992;22:83-103.

53. Martin JH, Pharmacologist C, Physician G, Medicine D. Pharmacogenetics of warfarin-is testing clinically indicated? Exp Clin Pharmacol. 2009;32:76-80.

54. Brantley SJ, Gufford BT, Dua R, Fediuk DJ, Graf TN, Scarlett YV, Fisher MB, Paine MF. Physiologically based pharmacokinetic modeling framework for quantitative prediction of an herb-drug interaction. CPT Pharmacometrics Syst Pharmacol. 2014;3:e107.

55. Zhang R, Sun J, Ma L, Wu X, Pan G, Hao H, Zhou F, Jiye A, Liu C, Shang LL, Ai H, Gao HY, Peng Y, Wu H, Wang GJ. Induction of cytochromes P450 1A1 and $1 \mathrm{~A} 2$ by tanshinones in human HepG2 hepatoma cell line. Toxicol Appl Pharmacol. 2011;252:18-27.

56. Lee WYW, Zhou X, Or PMY, Kwan YW, Yeung JHK. Tanshinone I increases CYP1A2 protein expression and enzyme activity in primary rat hepatocytes. Phytomedicine. 2012;19:169-76.

57. Kuo YH, Lin YL, Don MJ, Chen RM, Ueng YF. Induction of cytochrome P450-dependent monooxygenase by extracts of the medicinal herb Salvia miltiorrhiza. J Pharm Pharmacol. 2006;58:521-7.

58. Wu WWP, Yeung JHK. Inhibition of warfarin hydroxylation by major tanshinones of Danshen (Salvia miltiorrhiza) in the rat in vitro and in vivo. Phytomedicine. 2010;17:219-26.

59. Zhou LM, Chow MSS, Zuo Z. Effect of sodium caprate on the oral absorptions of danshensu and salvianolic acid B. Int J Pharm. 2009;379:109-18.

\section{Submit your next manuscript to BioMed Central and we will help you at every step:}

- We accept pre-submission inquiries

- Our selector tool helps you to find the most relevant journal

- We provide round the clock customer support

- Convenient online submission

- Thorough peer review

- Inclusion in PubMed and all major indexing services

- Maximum visibility for your research

Submit your manuscript at www.biomedcentral.com/submit

() Biomed Central 